\title{
Strength of Religious Faith in Peruvian Adolescents and Adults: Psychometric Evidence from the Original and Short Versions of the Santa Clara Strength of Religious Faith Questionnaire in Spanish
}

\author{
Tomás Caycho-Rodríguez ${ }^{1}$ (D) - Lindsey W. Vilca ${ }^{2}$-Thomas G. Plante ${ }^{3}$. \\ Andrea Vivanco-Vidal ${ }^{4}$ - Daniela Saroli-Araníbar ${ }^{5}$. Carlos Carbajal-León ${ }^{1}$. \\ Brian Norman Peña-Calero ${ }^{5} \cdot$ Michael White $^{6}$
}

Accepted: 21 July 2021 /Published online: 31 August 2021

(c) The Author(s), under exclusive licence to Springer Science+Business Media, LLC, part of Springer Nature 2021

\begin{abstract}
The aim of this study was to evaluate the psychometric evidence of the original and short versions of the Santa Clara Strength of Religious Faith Questionnaire (SCSRFQ) in Spanish in a sample of 245 Peruvian adolescents and adults (mean age $=21.04$ years, $\mathrm{SD}=3.07$, $47.8 \%$ male and $52.2 \%$ female), selected by nonprobabilistic convenience sampling. Additionally, the Coronavirus Anxiety Scale and the Satisfaction with Life Scale were applied. Confirmatory Factor Analysis, internal consistency reliability methods, hierarchical sequence of variance models, and a graded response model were used. Results indicate that both versions of the SCSRFQ showed robust psychometric properties: adequate unidimensional structure, adequate difficulty and discrimination parameters, and significant relationships with the measures of fear of COVID-19 and satisfaction with life. The original version of the SCSRFQ showed evidence of strict measurement invariance by sex and age, whereas the short version showed strict invariance by sex and configural invariance by age. Both versions showed acceptable reliability indices. In conclusion, the original and short versions of the SCSRFQ in Spanish show evidence of psychometric indicators that support their use to assess the strength of religious faith.
\end{abstract}

Keywords Reliability $\cdot$ Strength of faith $\cdot$ Invariance $\cdot$ Validity

Tomás Caycho-Rodríguez

tomas.caycho@upn.pe

1 Facultad de Ciencias de La Salud, Universidad Privada del Norte, Av. Alfredo Mendiola 6062, Los Olivos, Lima, Perú

2 Facultad de Ciencias de La Salud, Universidad Peruana Unión, Lima, Perú

3 Department of Psychology, Santa Clara University, Santa Clara, CA, USA

4 Facultad de Psicología, Universidad Peruana de Ciencias Aplicadas, Lima, Perú

5 Grupo de Estudios Avances en Medición Psicológica, Universidad Nacional Mayor de San Marcos, Lima, Perú

6 Dirección General de Investigación, Universidad Peruana Unión, Lima, Perú 
The religious landscape is dynamic and pluralistic in most Latin American countries, with a declining number of people who identify themselves as Catholics along with growth in the numbers of people who profess an evangelical faith tradition and those who do not practice any religion (Pew Research Center, 2014; Somma et al., 2017). This is not only a Latin American reality, as various studies suggest that in the last 40 years there has been a decrease in religious affiliation in the United States and various European countries (Dein et al., 2020). Despite the steady decline in the number of people who identify themselves as religious in the Western world, religion still plays an important role in the lives of many (Kranz et al., 2020). For example, religious faith is very important for most Peruvians; 92\% believe in God, 72\% consider themselves religious (WIN Gallup International, 2017), and "being well with God" is one of the main sources of happiness (Alarcón, 2002).

For some years now, the impact of religiosity and spirituality on the quality of life and well-being of people, whether healthy or ill, has been reported, promoting improved life satisfaction, greater hope, optimism, engagement with the local community, and bonding with friends and family, as well as lower rates of anxiety, depression, psychological distress, and lower risk of mortality (Abu et al., 2018; Bravin et al., 2019; Burlacu et al., 2019; Darviri et al., 2016; Dunbar, 2020; Lerman et al., 2018; Ng et al., 2017). The benefits of spiritual beliefs on mental health also affect physical health by decreasing the risk of contracting a disease and influencing the response to treatment (Del Castillo, 2020).

Epidemiological models of virus spread do not consider factors such as religious values (Dein et al., 2020) that promote spiritual support for people in times of crisis (Fardin, 2020). In the current COVID-19 pandemic, religiosity and spirituality have addressed the negative consequences of social isolation on mental health (Lucchetti et al., 2020). In addition, an increase in religious practices, such as time spent in prayer and other activities, has been observed (Boguszewski et al., 2020). In this regard, the number of searches for the word "prayer" on Google increased in 2020, doubling for every 80,000 newly diagnosed cases of COVID-19 (Bentzen, 2020). This suggests an increase in the actual number of people practicing prayer (Dein et al., 2020). Likewise, a recent survey indicated that 55\% of Americans prayed for the COVID-19 pandemic to end, which included 15\% who "rarely or never prayed" and $24 \%$ of people who prayed for the pandemic to go away but had no religious affiliation (Pew Research Center, 2020). Similarly, another survey indicated that $19 \%$ of Americans intensified their faith, whereas only $3 \%$ reported that it declined (Newport, 2020).

It has been suggested that religious faith facilitates adaptation to diseases and their consequences (Kowalczyk et al., 2020), making this a factor with important effects on health and well-being (Koenig et al., 2020). This is due to its benefits on the functioning of the immune system and vulnerability to viral infections, reducing the severity of disease and contributing to a faster recovery (Koenig, 2020). Similarly, a recent study indicated that young people between the ages of 21 and 35 indicated that faith and prayer were of great importance in the context of the COVID-19 pandemic; likewise, $64 \%$ of women stated that their faith would protect them from the dangers of the COVID-19 pandemic (Kowalczyk et al., 2020).

To effectively assess religious faith, as well as other spiritual and religious beliefs and behaviors, researchers need measures with adequate psychometric evidence. Many of these instruments, however, are specific to a particular type of religion; others assume that respondents have a religious affiliation or do not have sufficient empirical evidence to support their psychometric properties (Plante, 2010). Seeking to overcome these limitations, the Santa Clara Strength of Religious Faith Questionnaire (SCSRFQ; Plante \& Boccaccini, 1997) was developed as a measure of the strength of religious faith. 
The SCSRFQ defines faith as commitment to different spiritual and religious beliefs and institutions, while strength of faith refers to the importance of religious beliefs and practices in people's lives. These general definitions allow the SCSRFQ to assess an individual's faith independently of how it is defined in different religious traditions, which enables its use in different cultural contexts and without assuming that the respondent is religious or belongs to a specific religion, thus allowing the generalization and adaptability of the questionnaire (Plante, 2021).

The SCSRFQ is a short self-report measure (the original version has 10 items), free to use, and easy to administer and score, making it useful for researchers and health professionals who wish to examine the degree of strength of religious faith or use it as a variable in an investigation (Plante \& Boccaccini, 1997). In addition, the SCSRFQ has been translated into various languages, including English, Spanish, Portuguese, Italian, Czech, Polish, German, Chinese, and Farsi (Plante, 2021). Initially, the SCSRFQ was used in studies with patients with chronic diseases (e.g., Plante et al., 1999; Sherman et al., 1999), but it has also been implemented in other populations, such as college students (Storch et al., 2004a; Wnuk, 2017), older adults (Cummings et al., 2015), and people identified as gay, lesbian or bisexual (Walker \& Longmire-Avital, 2013), among others.

Several studies, in different cultural contexts, have shown that the SCSRFQ is a unidimensional measure of religious faith, with adequate reliability, that presents significant relationships with other variables such as religious life and orientation, intrinsic religious motivation, social provisions, social desirability, anxiety, emotional control, self-righteousness, optimism, spiritual experience, religious coping, negative and positive affect, religiosity and spirituality, spiritual well-being, depression and life satisfaction (Akin et al., 2015; Cummings et al., 2015; Dianni et al., 2014; Freiheit et al., 2006; Koukounaras Liagkis \& Ktenidis, 2021; Lewis et al., 2001; Pakpour et al., 2014; Plante \& Boccaccini, 1997; Plante et al., 1999; Sherman et al., 1999, 2001; Wnuk, 2017). Seeking to facilitate the use of the SCSRFQ in epidemiological research and the evaluation of patients with medical illnesses, a study conducted with samples of university students, women with cancer or cancer screening patients, and healthy women in a clinical setting developed a short version consisting of items 2, 4, 5, 8, and 10 of the original questionnaire (SCSRFQ-SF; Plante et al., 2002). The five items were selected on the basis of their high correlations with the total score of the original 10-item version, their moderate means, and their high standard deviations. This short version has also been shown to have a unidimensional structure, good internal consistency (Cronbach's alpha $=0.95$ ), high correlation with the original version of the questionnaire $(r=0.95)$, and significant correlations with the organizational, nonorganizational, and intrinsic dimensions of the Duke Religious Index ( $\mathrm{r}$ between -0.71 to-0.85) (Plante et al., 2002). Other psychometric studies conducted on university students have obtained similar results (Storch et al., 2004a, 2004b).

The psychometric analyses of the original and short versions of the SCSRFQ have been carried out based on procedures characteristic of the classical test theory (CTT). CTT procedures evaluate scales as an integrated whole and assume that people have an inherent attribute that can be measured through the numerical expression of an observed score, which is made up of the combination of the true score and the associated random error, where lower variability of the score would indicate higher precision of the measurement (observed score). In this sense, the CTT assumes that each item of the SCSRFQ has similar functioning and is equally accurate for measurements in people with low, medium, or high levels of faith strength and, therefore, that each item would provide the same amount of information (DeVellis, 2016; Furr, 2011). On the other hand, item response theory (IRT) overcomes the limitations of CTT (Embredson \& Reise, 2000) by assessing the 
relationships between the characteristics of the scale items (difficulty and discrimination), people's responses to the items, and the latent traits being measured (Steinberg \& Thissen, 2013). Thus, IRT procedures allow for estimating the precision (or greater information) with which each item measures a latent construct among people with different levels of that construct (Edelen \& Reeve, 2007). A study in older adults (Cummings et al., 2015) analyzed the original version of the SCSRFQ using IRT and reported that all items allowed for distinguishing between people with different levels of belief strength; furthermore, the SCSRFQ appeared to more accurately measure low to moderate levels of belief strength while poorly measuring very low and very high levels of belief. In this sense, the measurement of faith strength could be improved by understanding which items provide better information about people who have low, medium, or high levels of faith strength. The use of procedures derived from CTT and IRT would provide more robust psychometric results. No study, however, has evaluated the psychometric properties of the Spanish translation of the original and the short version of the SCSRFQ using both procedures in combination.

As a result, the present study aimed to examine the reliability, the validity evidence based on internal structure and the relationship with other variables (COVID-19 anxiety and life satisfaction), and measurement invariance by gender and age of the original and short versions of the SCSRFQ using structural equation modeling as well as the characteristics (difficulty and discrimination) of the items based on the IRT-derived graded response model. We expected the original and short versions of the SCSRFQ to have a unidimensional structure and high reliability estimates, as indicated by the literature (Plante, 2021). We also expected the SCSRFQ score to correlate positively with life satisfaction (Cummings et al., 2015; Freiheit et al., 2006; Hebert et al., 2009; Wnuk, 2017). Although there are no studies relating COVID-19 anxiety and faith strength, we expected a positive relationship, as noted in previous studies relating the latter variable to general anxiety symptoms (Plante et al., 2000, 2001). Similarly, we expected the SCSRFQ items to have adequate discrimination and difficulty parameters from IRT models, as indicated by the literature (Cummings et al., 2015).

On the other hand, the SCSRFQ has been used to compare the strength of faith between men and women as well as between different age groups, with some studies indicating that women and older people have higher scores (DeBono \& Kuschpel, 2014) while others reported no gender differences (Storch et al., 2004a). However, no measurement invariance studies of the SCSRFQ have been conducted that would test the equivalence of the measured construct between two or more groups to be sure that the same construct is assessed in each group and, therefore, the possible differences found between groups are true and not differences associated with the responses to the questionnaire items (Cheung \& Rensvold, 2002). Despite the absence of previous information on the invariance of the SCSRFQ measurement, we expected that the questionnaire would be invariant across different sex and age groups, as has been found for other questionnaires that assess aspects related to spirituality (Wink et al., 2021).

\section{Methodology}

\section{Participants}

A total of 245 adolescents and adults from the city of Lima, Peru, participated in the current study. The participants were selected by nonprobabilistic convenience sampling. The number of participants was determined based on the criteria of Muthén and Muthén (2002), who indicated 
that between 150 and 300 participants is sufficient for the psychometric study of unidimensional scales. The participants had an average age of 21.04 years $(\mathrm{SD}=3.07)$, and $117(47.8 \%)$ were male and $128(52.2 \%)$ were female. Of the participants, $75.5 \%$ had a permanent job, $13.1 \%$ had a temporary job, and $11.4 \%$ were unemployed. The majority $(90.6 \%)$ had been diagnosed with COVID-19 and had family members diagnosed with the disease (73.9\%). In addition, $63.7 \%$ reported having been exposed to between 1 and $3 \mathrm{~h}$ of information about COVID-19, and 54.7\% indicated having left home less than a day or two in the past two weeks. Finally, $70.2 \%$ reported living with vulnerable people (children, elderly, chronically ill).

\section{Instruments}

Santa Clara Strength of Religious Faith Questionnaire (SCSRFQ; Plante \& Boccaccini, 1997) This is a self-report measure of religious faith strength, originally consisting of 10 items with 4 Likert-type response options ( $1=$ strongly disagree to $4=$ strongly agree $)$. The total score of the SCSRFQ ranges from 10 to 40. The short version of the SCSRFQ is composed of 5 items (items 2, 4, 5, 8 and 10) derived from the original questionnaire (SCSRFQ-SF; Plante et al., 2002). Like the original version, the total score is obtained from the sum of all items and varies between 5 and 20. In both versions, higher scores express greater strength of religious faith.

Coronavirus Anxiety Scale (CAS; Lee, 2020) This self-report measure is made up of 5 items that identify the frequency of physiological symptoms generated by thoughts and information related to COVID-19 during the previous 2 weeks. The version validated for the general population of Peru (Rodriguez et al. 2021) was used in which each item has 5 response options ranging from 0 (not at all) to 4 (almost every day). The sum of the scores for each item provides a total CAS score ranging from 0 to 20 , where a higher score indicates a higher frequency of anxiety symptoms related to COVID-19. In this study, the CAS had adequate internal consistency reliability $(\alpha=0.93)$.

Satisfaction with Life Scale (SWLS; Diener et al., 1985) This is made up of 5 items that assess a person's general feeling of satisfaction with their life. The version validated in Peru was used (Oliver et al., 2018). The items have 5 Likert-type response options $(1=$ strongly disagree to $5=$ strongly agree), where the sum of the scores for each item provides a total score ranging from 5 to 25 . A higher score indicates greater overall satisfaction with life. In this study, the SWLS had adequate internal consistency reliability $(\alpha=0.90)$.

\section{Procedure}

An instrumental study (Ato et al., 2013) was carried out by conducting an online survey between July and August 2020. The survey was available on the Google Forms platform and took approximately $15 \mathrm{~min}$ to complete. Due to the restrictions on social interaction imposed by the Peruvian government to mitigate the spread of COVID-19, the web link to the survey was shared via email and/or social networks (Facebook, Instagram, Twitter). The study was reviewed and approved by the Ethics Committee of the Universidad Privada del Norte and followed the ethical standards of the Declaration of Helsinki. In the first part of the survey, participants were informed about the objective of the study, the anonymous nature of their responses, and the use that would be made of the information collected. Electronic informed consent was obtained from the participants. 


\section{Data Analysis}

First, descriptive statistics were calculated for the SCSRFQ items (mean [M], standard deviation [SD], skewness [g1], and kurtosis [g2]). Second, two confirmatory factor analyses (CFA) were performed, one to assess the internal structure of the original and short versions of the SCSRFQ and the other to assess the evidence of validity in relation to other constructs for both scales. In this second CFA, hypothetical models were tested in which the strength of faith was related to the degree of anxiety about COVID-19 and satisfaction with life. For both CFAs, the Diagonally Weighted Least Squares with Mean and Variance corrected (WLSMV) estimator was used because the SCSRFQ items are ordinal in nature (Brown, 2015). To evaluate the fit of the models, the chi-square test $(\chi 2)$ was used, as well as the root mean square error of approximation (RMSEA) and the standardized root mean square residual (SRMR) indices, where values less than 0.05 indicate good fit and between 0.05 and 0.08 acceptable fit (Kline, 2015). In addition, the comparative fit index (CFI) and Tucker-Lewis index (TLI) were used, where values greater than 0.95 indicate good fit and greater than 0.90 acceptable fit (Schumacker \& Lomax, 2015). To assess the internal consistency of the scale, Cronbach's alpha coefficient (Cronbach, 1951) and the omega coefficient (McDonald, 1999) were used, where a value of $\omega>0.80$ is adequate (Raykov \& Hancock, 2005).

Third, the invariance of the original and short versions of the SCSRFQ was evaluated according to the sex and age of the participants. For this purpose, a sequence of increasingly restrictive hierarchical variance models was proposed. Initially, configural invariance (reference model) was evaluated, followed by metric invariance (equality of factor loadings), scalar invariance (equality of factor loadings and intercepts), and finally strict invariance (equality of factor loadings, intercepts, and residuals). To compare the sequence of models, we first employed a formal statistical test: the chi-square difference $(\Delta \chi 2)$, where nonsignificant values $(\mathrm{p}>0.05)$ suggest invariance between groups. Likewise, a modeling strategy was employed for which the difference in CFI ( $\triangle \mathrm{CFI})$ was used, where values less than $<0.010$ evidence model invariance, as well as the difference in RMSEA ( $\Delta$ RMSEA), where values less than $<0.015$ evidence model invariance between groups (Chen, 2007).

The SCSRFQ was also evaluated on the basis of IRT. With this in mind, a graded response model (GRM; Samejima, 1997) was employed, specifically an extension of the 2-parameter logistic model (2-PLM) for ordered polytomous items (Hambleton et al., 2010). For each item, two types of parameters were estimated: discrimination (a) and difficulty (b). The discrimination parameter (a) determines the slope at which item responses vary as a function of the level of the latent trait. The difficulty parameter (b) determines how much of the latent trait the item requires to be answered by the participants. Since the original and short versions of the SCSRFQ have four response categories, three estimates of the difficulty parameter were obtained. The estimates for these three thresholds indicate the level of the latent variable at which an individual has a $50 \%$ chance of scoring at or above the response category related to the threshold. Item information curves (IIC) and test information curves (TIC) were also calculated for both versions.

Data analysis was performed in the RStudio environment (RStudio Team, 2018) for R (R Core Team, 2019). The "lavaan" package (Rosseel, 2012), the "semTools" package for factorial invariance (Jorgensen et al., 2018), and the "ltm" package for the GRM (Rizopoulos, 2006) were used for the CFAs. 


\section{Results}

\section{Descriptive Analysis of the Original Version and Short Version Items}

Table 1 shows that item 7 (My relationship with God is extremely important to me) has the highest mean score in the total sample $(M=2.64)$ and in the specific groups of males $(M=2.69)$, females $(M=2.59)$, adolescents $(M=2.78)$, and adults $(M=2.49)$. Item 5 (I consider myself active in my faith or church) presents the lowest mean score in the total sample $(M=2.06)$ and in the specific groups of males $(M=2.10)$, females $(M=2.02)$, adolescents $(M=2.21)$, and adults $(M=1.90)$. In addition, all items present adequate skewness and kurtosis indices $( \pm 1.5)$ in the total sample and in all specific groups.

\section{Validity Based on the Internal Structure of Both Scales}

Table 2 shows that the unidimensional model of the original version of the SCSRFQ evidences acceptable fit indices in the total sample $(\chi 2=99.19 ; \mathrm{df}=35 ; \mathrm{p}=0.000 ; \mathrm{CFI}=0.99$; $\mathrm{TLI}=0.99 ; \mathrm{RMSEA}=0.087)$ and the samples of males $(\chi 2=67.94 ; \mathrm{df}=35 ; \mathrm{p}=0.001$; $\mathrm{CFI}=0.99 ; \quad \mathrm{TLI}=0.99 ; \quad$ RMSEA $=0.090)$, females $\quad(\chi 2=85.16 ; \mathrm{df}=35 ; \mathrm{p}=0.000 ;$ $\mathrm{CFI}=0.99 ; \mathrm{TLI}=0.98 ; \mathrm{RMSEA}=0.106)$, adolescents $(\chi 2=105.75 ; \mathrm{df}=35 ; \mathrm{p}=0.000$; $\mathrm{CFI}=0.99 ; \mathrm{TLI}=0.98 ; \mathrm{RMSEA}=0.126)$, and adults $(\chi 2=67.10 ; \mathrm{df}=35 ; \mathrm{p}=0.001$; $\mathrm{CFI}=0.99$; $\mathrm{TLI}=0.99$; RMSEA =0.089). In addition, it can be seen that in the total sample and in the specific groups, the factor loadings are high and significant (see Table 4).

Table 3 shows that the unidimensional model of the short version of the SCSRFQ presents acceptable adjustment indexes in the total sample $\left(\chi^{2}=14.19 ; \mathrm{df}=5 ; \mathrm{p}=0.014\right.$; $\mathrm{CFI}=0.99 ; \mathrm{TLI}=0.99 ; \mathrm{RMSEA}=0.087)$ and the samples of men $\left(\chi^{2}=6.28 ; \mathrm{df}=5\right.$; $\mathrm{p}=0.279 ; \mathrm{CFI}=0.99 ; \mathrm{TLI}=0.99 ; \mathrm{RMSEA}=0.047)$, women $\left(\chi^{2}=11.43 ; \mathrm{df}=5 ; \mathrm{p}=0.043\right.$; $\mathrm{CFI}=0.99 ; \quad \mathrm{TLI}=0.99 ; \quad$ RMSEA $=0.101), \quad$ adolescents $\left(\chi^{2}=2.11 ; \mathrm{df}=5 ; \quad \mathrm{p}=0.834 ;\right.$ $\mathrm{CFI}=1.00 ; \mathrm{TLI}=1.00 ; \mathrm{RMSEA}=0.000)$, and adults $\left(\chi^{2}=18.19 ; \mathrm{df}=5 ; \mathrm{p}=0.003\right.$; $\mathrm{CFI}=0.99$; $\mathrm{TLI}=0.99$; RMSEA $=0.151)$. Likewise, the factor loadings of the items are high and significant in all groups (see Table 4).

\section{Factorial Invariance of Both Scales According to Sex and Age}

Regarding the original version of the SCSRFQ, the factor structure shows evidence of being strictly invariant between male and female groups based on the sequence of invariance models posed: metric $(\Delta \chi 2=7.24, p=0.612, \Delta \mathrm{CFI}=0.007)$, scalar $(\Delta \chi 2=6.65$, $p=0.673, \Delta \mathrm{CFI}=-0.000)$, and strict $(\Delta \chi 2=7.50, p=0.677, \Delta \mathrm{CFI}=0.000)$ invariance. Similarly, the SCSRFQ also showed evidence of being strictly invariant between adolescents and adults: metric $(\Delta \chi 2=15.29, p=0.083, \Delta \mathrm{CFI}=-0.007)$, scalar $(\Delta \chi 2=19.31$, $p=0.022, \Delta \mathrm{CFI}=-0.004)$, and strict $(\Delta \chi 2=12.69, p=0.241, \Delta \mathrm{CFI}=0.001)$ invariance. The results can be seen in Table 3 .

Similarly, in the short version of the SCSRFQ, the findings presented in Table 3 indicate that the factor structure shows evidence of being strictly invariant between males and females: metric $(\Delta \chi 2=3.32, p=0.504, \Delta \mathrm{CFI}=0.001)$, scalar $(\Delta \chi 2=0.87, p=0.928$, $\Delta \mathrm{CFI}=-0.000)$, and strict $(\Delta \chi 2=3.10, p=0.684, \Delta \mathrm{CFI}=-0.000)$ invariance. However, the scale only evidences configural invariance between adolescents and adults: metric 


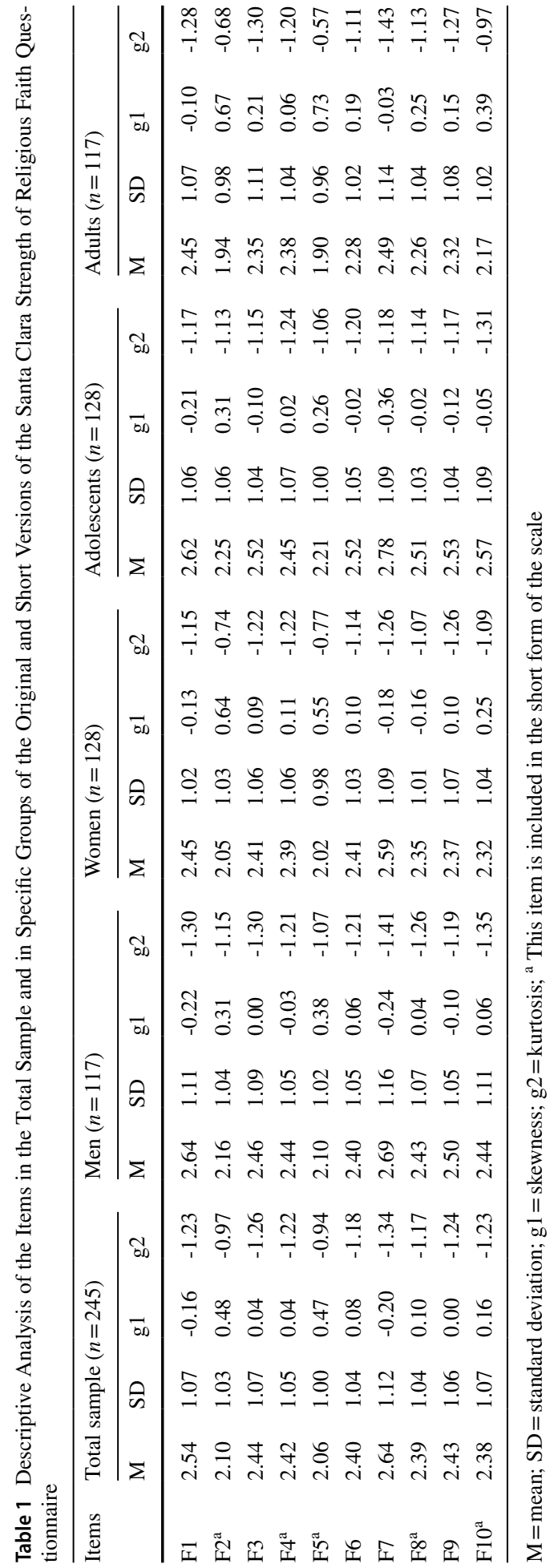




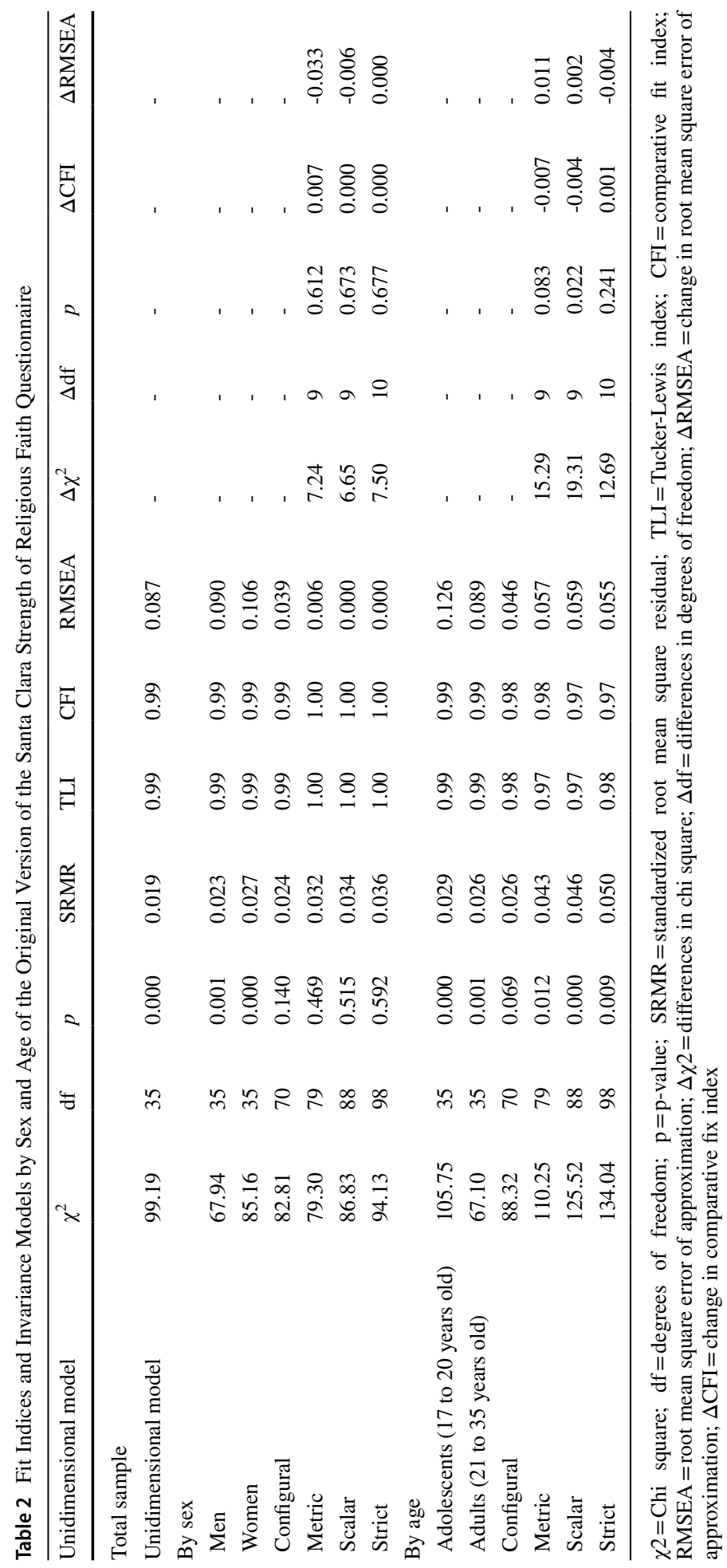




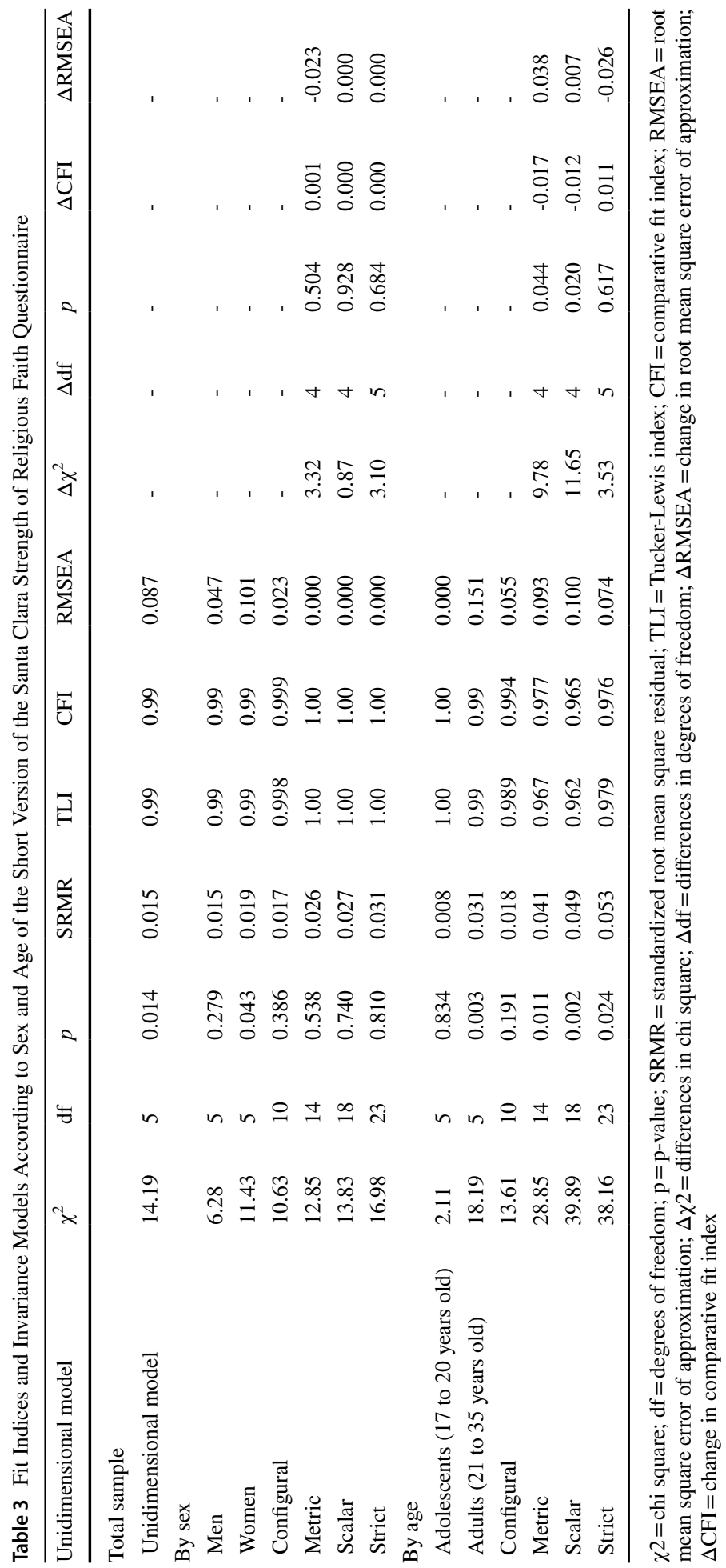




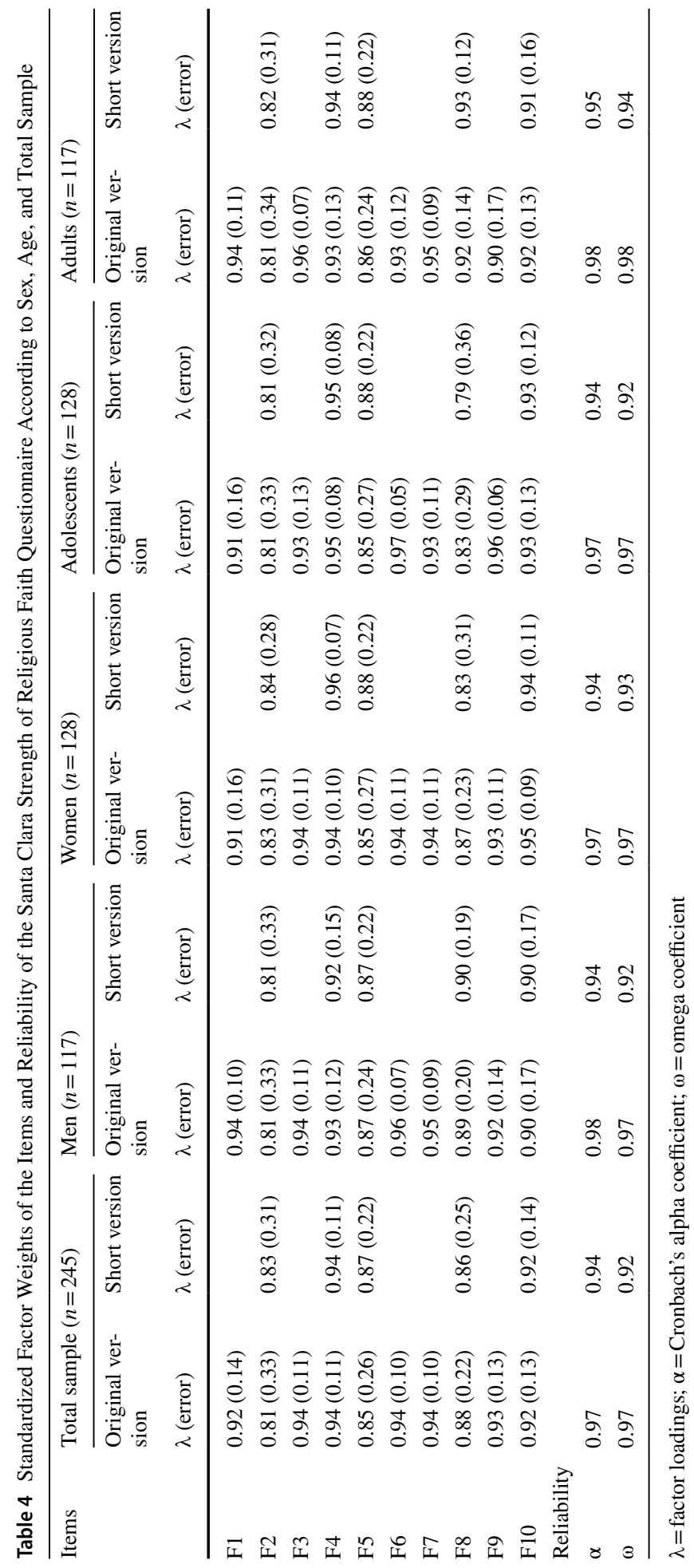


$(\Delta \chi 2=9.78, p=0.044, \Delta \mathrm{CFI}=-0.017)$, scalar $(\Delta \chi 2=11.65, p=0.020, \Delta \mathrm{CFI}=-0.012)$. and strict $(\Delta \chi 2=3.53, p=0.617, \Delta \mathrm{CFI}=0.011)$ invariance.

\section{Reliability of Both Scales}

The original version of the SCSRFQ presents adequate reliability indices $(\alpha=0.97$; $\omega=0.97)$ in the total sample as well as in the groups of men $(\alpha=0.98 ; \omega=0.97)$, women $(\alpha=0.97 ; \omega=0.97)$, adolescents $(\alpha=0.97 ; \omega=0.97)$, and adults $(\alpha=0.98 ; \omega=0.98)$. Similar results are observed when assessing the reliability of the short version of the SCSRFQ in the total sample $(\alpha=0.94 ; \omega=0.92)$, men $(\alpha=0.94 ; \omega=0.92)$, women $(\alpha=0.94$; $\omega=0.93)$, adolescents $(\alpha=0.94 ; \omega=0.92)$, and adults $(\alpha=0.95 ; \omega=0.94)$. The results can be seen in Table 4.

\section{Item Response Theory Model: Graded Response Model}

A graded response model (GRM), specifically a 2-PLM model, was fitted for each version of the SCSRFQ. Table 5 shows that all item discrimination parameters for both versions are above the value of 1 , generally considered good discrimination (Hambleton et al., 2010). Regarding the difficulty parameters, in both versions all threshold estimators increased monotonically, as expected.

Figure 1 shows the IIC and TIC. For the original version of the SCSRFQ, the IIC shows that items 4 and 6 are the most accurate in assessing the latent trait. In addition, the TIC shows that the factor is more reliable (accurate) in the range of the scale between -1 and 1.5. Regarding the short version, the IIC shows that items 2 and 5 are the most accurate in assessing the latent trait. In addition, the TIC shows that the factor is more reliable (accurate) in the range of the scale between -1 and 1.5 .

Table 5 Discrimination and Difficulty Parameters for the Items of Each Dimension of the Santa Clara Strength of Religious Faith Questionnaire

\begin{tabular}{llllll}
\hline Version of the scale & Item & $\mathrm{a}$ & $\mathrm{b}_{1}$ & $\mathrm{~b}_{2}$ & $\mathrm{~b}_{3}$ \\
\hline Original version & F1 & 3.20 & -1.02 & 0.00 & 1.17 \\
& F2 & 2.03 & -0.07 & 0.92 & 1.85 \\
& F3 & 3.70 & -0.65 & 0.30 & 0.99 \\
& F4 & 4.12 & -0.63 & 0.27 & 1.04 \\
& F5 & 2.21 & -0.08 & 0.73 & 1.69 \\
& F6 & 4.05 & -0.66 & 0.32 & 1.11 \\
& F7 & 3.34 & -1.00 & 0.09 & 0.87 \\
& F8 & 2.46 & -0.71 & 0.37 & 1.31 \\
& F9 & 2.96 & -0.79 & 0.22 & 1.05 \\
Short version & F10 & 3.67 & -0.54 & 0.42 & 0.95 \\
& F1 & 2.98 & -0.25 & 0.68 & 1.47 \\
& F2 & 4.15 & -0.58 & 0.25 & 0.98 \\
& F3 & 3.71 & -0.23 & 0.58 & 1.27 \\
& F4 & 3.44 & -0.67 & 0.34 & 1.12 \\
& F5 & 4.17 & -0.64 & 0.28 & 0.86 \\
\hline
\end{tabular}

$a=$ discrimination parameters $; b=$ difficulty parameters 


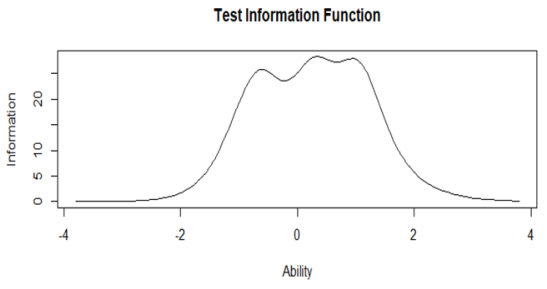

Test Information Curves (TIC) of the SCSRFQoriginal version

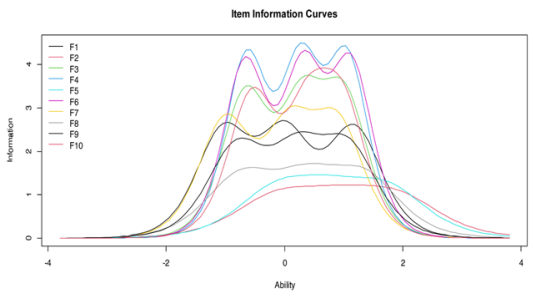

Item Information Curves (IIC) of the SCSRFQoriginal version

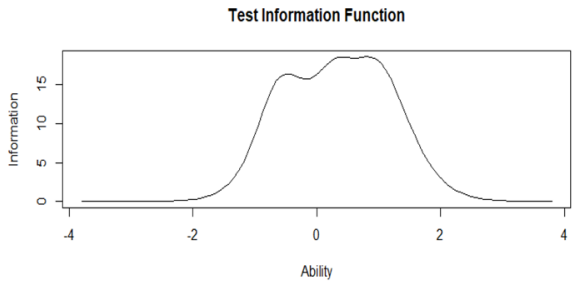

Test Information Curves (TIC) of the SCSRFQshort version

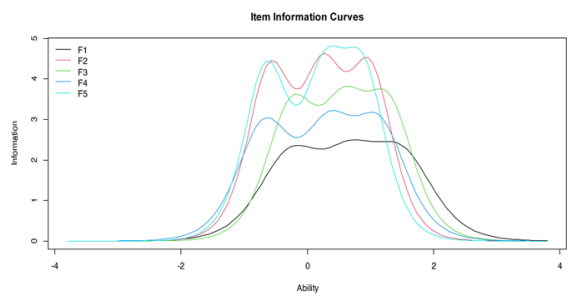

Item Information Curves (IIC) of the SCSRFQshort version

Figure 1. Test Information Curves (TIC) and Item Information Curves (IIC) of the Original and Short Version of the of the Santa Clara Strength of Religious Faith Questionnaire (SCSRFQ)

\section{Validity Based on the Relationship to Other Constructs}

Taking into account the literature review, several individual models were proposed to evaluate the relationship between the strength of faith construct and other constructs. For the original version of the SCSRFQ, Fig. 2 presents model 1 relating strength of faith and anxiety related to COVID-19, which has excellent fit indices $(\chi 2=128.02 ; \mathrm{df}=89 ; \mathrm{p}=0.004$; RMSEA $=0.042 ; \mathrm{CFI}=0.99 ; \mathrm{TLI}=0.99)$, and both variables have a positive relationship $(r .26 ; \mathrm{p}<0.01)$. In model 2 , the relationship between faith strength and life satisfaction

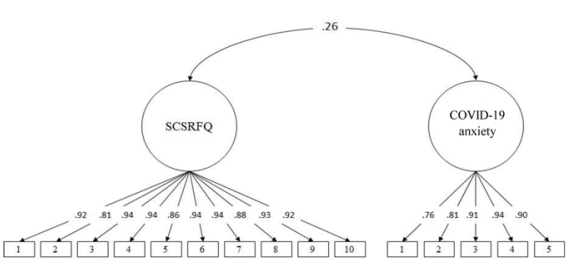

Model 1. Relationship between faith strength and COVID-19 anxiety

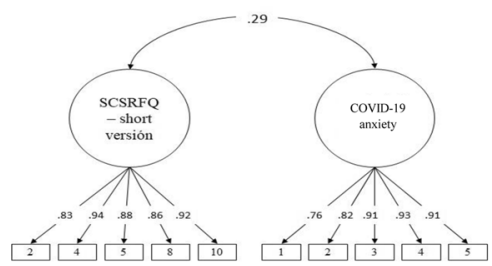

Model 3. Relationship between faith strength and COVID-19 anxiety

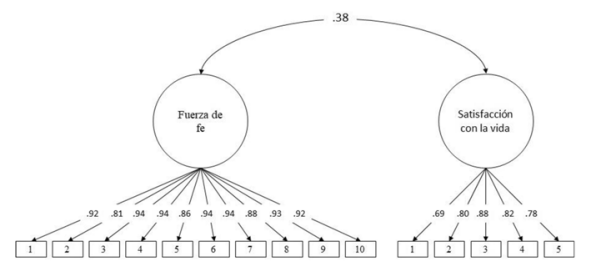

Model 2. Relationship between strength of faith and satisfaction with life
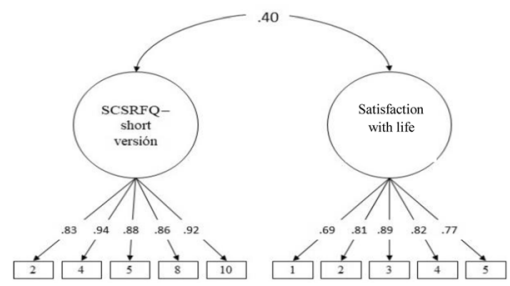

Model 4. Relationship between strength of faith and satisfaction with life

Figure 2. Relationship Models of the Original and Short Versions of the Santa Clara Strength of Religious Faith Questionnaire (SCSRFQ) With Other Constructs 
presents adequate fit indices $(\chi 2=145.31 ; \mathrm{df}=89 ; \mathrm{p}=0.000 ; \mathrm{RMSEA}=0.051 ; \mathrm{CFI}=0.99$; $\mathrm{TLI}=0.99)$, where both variables have a positive relationship $(r .38 ; \mathrm{p}<0.01)$.

Regarding the short version of the SCSRFQ scale, Fig. 2 shows that model 1 of the relationship between faith strength and anxiety related to COVID-19 presents adequate adjustment indexes $(\chi 2=43.77 ; \mathrm{df}=34 ; \mathrm{p}=0.122$; RMSEA $=0.034 ; \mathrm{CFI}=0.99$; TLI $=0.99)$ and both variables have a positive relationship $(r .29 ; \mathrm{p}<0.01)$. Model 2 of the same figure shows the relationship between faith strength and life satisfaction, which presents adequate fit indices $(\chi 2=55.44 ; \mathrm{df}=34 ; \mathrm{p}=0.012$; $\mathrm{RMSEA}=0.051 ; \mathrm{CFI}=0.99$; $\mathrm{TLI}=0.99)$ and both variables have a positive relationship $(r .40 ; \mathrm{p}<0.01)$.

\section{Discussion}

The SCSRFQ was created to provide a quick, simple, and useful measure of religious faith strength that can be used in research and practice by mental health professionals. Moreover, because its items do not refer to any specific religious orientation, it can be used with people with any religious affiliation. In this sense, the aim of the study was to examine the reliability, the evidence of validity based on the internal structure and the relationship with other variables, and the invariance of the measurement according to sex and age as well as the characteristics (difficulty and discrimination) of the items of the original and short versions of the SCSRFQ in Spanish.

The unidimensional structure of the original (10 items) and short (5 items) versions of the SCSRFQ in Spanish had an adequate fit, and all items loaded significantly on the latent factor religious faith strength, both in the total sample and in the sex and age subgroups. Therefore, the present study replicates previous findings reported in the literature (Akin et al., 2015; Cummings et al., 2015; Dianni et al., 2014; Freiheit et al., 2006; Koukounaras Liagkis \& Ktenidis, 2021; Lewis et al., 2001; Pakpour et al., 2014; Plante, 2021; Plante \& Boccaccini, 1997; Plante et al., 1999, 2002; Sherman et al., 1999, 2001; Storch et al., 2004a, b; Wnuk, 2017). Thus, each item reflects only one latent construct and not another (Gefen, 2003). If this were not the case and one or more items measured not only strength of faith but also another aspect related to spirituality, the total SCSRFQ score would contain this information and could not be used to interpret a person's position on the latent variable strength of faith (Ziegler \& Hagemann, 2015). In addition, both versions of the SCSRFQ presented adequate values of reliability coefficients.

The results of the GRM analysis indicated that the discrimination parameters of the items were high (above 2) in both versions of the SCSRFQ. Thus, all items are adequate to differentiate the responses of people with different levels of faith strength. In the original version, items $3,4,6$, and 10 present the highest discrimination parameters and refer to the strength of faith as a source of inspiration, meaning, identity, and decision making. Similarly, in the short version items 2 and 5 have the highest discrimination parameters and also refer to the strength of faith as a source of meaning and decision making. This means that situations and/or items related to these themes will allow people to choose highly differentiated response alternatives even if some of them have similar levels of faith strength.

Likewise, the difficulty parameters in both versions increased monotonically, indicating that as people have greater strength of faith, they will tend to choose positive and higher response alternatives. In the complete and short versions, items 1 and 2 require a greater latent trait on the part of the participants, so they have a probability greater than or equal to $50 \%$ of being able to choose the alternative of agreeing totally with the statement. How- 
ever, the rest of the response alternatives of these same items require amounts of the latent trait that do not differ greatly from the last threshold (b3), so these items end up being the least informative in both versions of the test. Despite this, the remaining items demonstrate excellent performance in the average population, so the SCSRFQ can be used as a general measurement instrument across the different age groups tested.

Testing the unidimensionality and reliability of the SCSRFQ allows it to be used to investigate connections between faith strength and other mental health variables. In this regard, SCSRFQ scores correlated positively with COVID-19 anxiety and life satisfaction. These correlation patterns allowed us to confirm previous hypotheses, providing additional evidence on the validity of the SCSRFQ among Peruvian youth and adults. In the case of the positive relationships between faith strength and COVID-19 anxiety, it seems to suggest that the negative pressure of the pandemic on people's mental health intensified their faith along with other religious practices, such as prayer, reflecting their seeking protection against the dangers of the COVID-19 pandemic (Boguszewski et al., 2020; Kowalczyk et al., 2020; Newport, 2020). Similarly, the relationship between the latent variables life satisfaction and faith strength would indicate that the latter is a positive and cognitive indicator for maintaining well-being (Koenig, 2020; Wnuk, 2017).

On the other hand, the present study extended previous findings by evaluating the measurement invariance of the original and short versions of the SCSRFQ in Spanish. Results indicate that configural, metric, scalar, and strict invariance of the original and short versions of the SCSRFQ was maintained in both sexes. Specifically, the configural invariance assessment suggests that youth and adults of both sexes conceptualize religious strength of faith in the same unidimensional structure; metric invariance suggests that a change in the construct strength of faith causes the same change in SCSRFQ scores between the compared groups; scalar invariance indicates the relationship between the observed and latent SCSRFQ score is invariant; and strict invariance suggests that the SCSRFQ measures strength of faith with equivalent measurement error between men and women. Therefore, the unidimensional structure is equivalent and the original version of the SCSRFQ measures the same construct strength of faith across different sex groups (Van de Schoot et al., 2012). In addition, strict invariance assesses random error variability and systematic variability generated by unspecified sources of variation, thus also providing complementary information on reliability (Wu et al., 2007). In this sense, the strict invariance analysis indicates that the SCSRFQ items are equally reliable between men and women. Likewise, the short version of the SCSRFQ showed strict invariance between the male and female groups; however, it only presented configural invariance when comparing the adolescent and adult groups. The absence of metric, scalar, and strict invariance between age groups does not provide a sound psychometric basis for using the short version of the SCSRFQ to compare the means of the latent factor strength of faith between adolescents and adults.

The study has some limitations that should be mentioned to guide the direction of future research. First, because the data were collected through nonprobability sampling from a single city (Lima, Peru), the results may be limited as they cannot be generalized to the entire population of adolescents and adults in Peru. In this sense, future studies should use nationally representative samples to confirm the findings presented here. In addition, further psychometric work could be conducted with clinical samples along with the general population to assess the criterion validity of the questionnaire. Second, the study design was cross-sectional and, therefore, the reported relationships between the variables faith strength, COVID-19 anxiety, and life satisfaction provide limited information on causality. Thus, longitudinal studies during this pandemic or others that are conducted in the future may help to better understand the impact of religious faith strength on COVID-19 anxiety 
and life satisfaction. Third, the temporal stability of the SCSRFQ was not assessed, so it would be useful to assess this aspect in the future. Fourth, self-report measures may not be the best choice for investigating aspects related to spirituality and religiosity because they involve a complex set of feelings and beliefs. In addition, self-report measures are associated with biases, such as social desirability (Rosenman et al., 2011). Therefore, it is recommended that future studies employ other methodologies to obtain information, such as in-depth interviews.

Despite the aforementioned limitations, this study is the first to evaluate the psychometric properties of the original and short versions of the SCSRFQ in Spanish using traditional (structural equation modeling) and modern (IRT) procedures. In addition, the SCSRFQ is a measure that can be administered in a short period of time, and it provides information about the degree to which the strength of religious faith can be an important variable within the processes of mental health research and treatment. Regarding the former, the SCSRFQ may be useful in studies seeking a better understanding of the impact of spirituality on health outcomes. Additionally, people with greater faith strength may be likely to be part of mental health interventions that include spiritual or religious dimensions (Tan, 2013). For example, cognitive-behavioral therapies that have incorporated spiritual beliefs and practices have been promoted for some years and are considered empirically validated interventions for members of various religious groups (Hook et al., 2010; Koenig \& Al Shohaib, 2014).

The quality of research depends, to a certain extent, on the precision of the instruments used to collect the information, even more so if the instruments evaluate complex phenomena related to spirituality, such as faith. In this sense, the findings of the validation process of the original and short versions of the SCSRFQ in Spanish have allowed us to establish that the measurement of a complex construct such as the strength of faith can be carried out with high levels of psychometric quality. Thus, both versions of the SCSRFQ are valid and reliable measures to assess the strength of religious faith in young people and adults.

\section{References}

Abu, H. O., Ulbricht, C., Ding, E., Allison, J. J., Salmoirago-Blotcher, E., Goldberg, R. J., \& Kiefe, C. I. (2018). Association of religiosity and spirituality with quality of life in patients with cardiovascular disease: A systematic review. Quality of Life Research, 27(11), 2777-2797. https://doi.org/10.1007/ s11136-018-1906-4

Akin, A., Turan, M. E., \& Altundağ, Y. (2015). The validity and reliability of Turkish version of the Santa Clara Strength of Religious Faith Questionnaire. Journal of Educational \& Instructional Studies in the World, 5(1), 35-38.

Alarcón, R. (2002). Fuentes de felicidad: ¿Qué hace feliz a la gente? Revista De Psicología, 20(2), 169-196.

Ato, M., López-García, J. J., \& Benavente, A. (2013). Un sistema de clasificación de los diseños de investigación en psicología. Anales de Psicología, 29(3), 1038-1059. https://doi.org/10.6018/analesps.29.3. 178511

Bentzen, J. (2020). In crisis, we pray: Religiosity and the COVID-19 pandemic. Covid Economics: Vetted and Real-Time Papers, 20, 52-79. https://papers.ssrn.com/sol3/papers.cfm?abstract_id=3615587

Boguszewski, R., Makowska, M., Bożewicz, M., \& Podkowińska, M. (2020). The COVID-19 pandemic's impact on religiosity in Poland. Religions, 11(12), 646. https://doi.org/10.3390/rel11120646

Bravin, A. M., Trettene, A. D. S., Andrade, L. G. M. D., \& Popim, R. C. (2019). Benefits of spirituality and/or religiosity in patients with chronic kidney disease: An integrative review. Revista Brasileira De Enfermagem, 72(2), 541-551. https://doi.org/10.1590/0034-7167-2018-0051

Brown, T. A. (2015). Confirmatory Factor Analysis for Applied Research (2 ${ }^{\text {nd }}$ ed.). New York, NY: Guilford Press. https://books.google.com.pe/books?id=tTL2BQAAQBAJ 
Burlacu, A., Artene, B., Nistor, I., Buju, S., Jugrin, D., Mavrichi, I., \& Covic, A. (2019). Religiosity, spirituality and quality of life of dialysis patients: A systematic review. International Urology and Nephrology, 51(5), 839-850. https://doi.org/10.1007/s11255-019-02129-X

Chen, F. F. (2007). Sensitivity of goodness of fit indexes to lack of measurement invariance. Structural Equation Modeling, 14(3), 464-504. https://doi.org/10.1080/10705510701301834

Cheung, G. W., \& Rensvold, R. B. (2002). Evaluating goodness-of-fit indexes for testing measurement invariance. Structural Equation Modeling, 9(2), 233-255. https://doi.org/10.1207/S15328007SEM0902_5

Cronbach, L. J. (1951). Coefficient alpha and the internal structure of tests. Psychometrika, 16(3), 297334. https://doi.org/10.1007/BF02310555

Cummings, J. P., Carson, C. S., Shrestha, S., Kunik, M. E., Armento, M. E., Stanley, M. A., \& Amspoker, A. B. (2015). Santa Clara Strength of Religious Faith Questionnaire: Psychometric analysis in older adults. Aging \& Mental Health, 19(1), 86-97. https://doi.org/10.1080/13607863.2014.917606

Darviri, C., Artemiadis, A., Tigani, X., Darvyri, P., \& Gnardellis, C. (2016). Religiosity as a predictor of mortality: A retrospective cohort study in 1519 rural citizens in Greece. Psychology \& Health, 31(9), 1080-1090. https://doi.org/10.1080/08870446.2016.1178744

DeBono, K. G., \& Kuschpel, A. (2014). Gender differences in religiosity: The role of self-monitoring. North American Journal of Psychology, 16(2), 415-425.

Dein, S., Loewenthal, K., Lewis, C. A., \& Pargament, K. I. (2020). COVID-19, mental health and religion: An agenda for future research. Mental Health, Religion \& Culture, 23, 1-9. https://doi.org/10. 1080/13674676.2020.1768725

Del Castillo, F. (2020). Health, spirituality and Covid-19: Themes and insights. Journal of Public Health, 43(2), e254-e255. https://doi.org/10.1093/pubmed/fdaa185

DeVellis, R. F. (2016). Scale development: Theory and applications. London: Sage.

Dianni, M., Proios, M., \& Kouthouris, C. (2014). Structural validity of 'Santa Clara Strength of Religious Faith Questionnaire' in Greek sample. Religions, 5(1), 157-164. https://doi.org/10.3390/rel5010157

Diener, E. D., Emmons, R. A., Larsen, R. J., \& Griffin, S. (1985). The satisfaction with life scale. Journal of Personality Assessment, 49(1), 71-75. https://doi.org/10.1207/s15327752jpa4901_13

Dunbar, R. I. (2020). Religiosity and religious attendance as factors in wellbeing and social engagement. Religion, Brain \& Behavior, 11(1), 17-26. https://doi.org/10.1080/2153599X.2020.1712618

Edelen, M. O., \& Reeve, B. B. (2007). Applying item response theory (IRT) modeling to questionnaire development, evaluation, and refinement. Quality of Life Research, 16(1), 5-18. https://doi.org/10. 1007/s11136-007-9198-0

Embredson, S. E., \& Reise, S. P. (2000). Item response theory for psychologists. Erlbaum.

Fardin, M. A. (2020). COVID-19 epidemic and spirituality: A review of the benefits of religion in times of crisis. Jundishapur Journal of Chronic Disease Care, 9(2), e104260. https://doi.org/10.5812/ jjcdc. 104260

Freiheit, S. R., Sonstegard, K., Schmitt, A., \& Vye, C. (2006). Religiosity and spirituality: A psychometric evaluation of the Santa Clara Strength of Religious Faith Questionnaire. Pastoral Psychology, 55(1), 27-33. https://doi.org/10.1007/s11089-006-0029-y

Furr, R. M. (2011). Scale construction and psychometrics for social and personality psychology. Sage.

Gefen, D. (2003). Assessing unidimensionality through LISREL: An explanation and an example. Communications of the Association for Information Systems, 12(1), 2. https://doi.org/10.17705/1CAIS. 01202

Hambleton, R. K., van der Linden, W. J., \& Wells, C. S. (2010). IRT models for the analysis of polytomously scored data: Brief and selected history of model building advances. In M. L. Nering \& R. Ostini (Eds.), Handbook of polytomous item response models (pp. 21-42). New York: Routledge.

Hebert, R., Zdaniuk, B., Schulz, R., \& Scheier, M. (2009). Positive and negative religious coping and well-being in women with breast cancer. Journal of Palliative Medicine, 12(6), 537-545. https:// doi.org/10.1089/jpm.2008.0250

Hook, J. N., Worthington, E. L., Jr., Davis, D. E., Jennings, D. J., Gartner, A. L., \& Hook, J. P. (2010). Empirically supported religious and spiritual therapies. Journal of Clinical Psychology, 66(1), 46-72. https://doi.org/10.1002/jclp.20626

Jorgensen, T. D., Pornprasertmanit, S., Schoemann, A. M., \& Rosseel, Y. (2018). semTools: Useful tools for structural equation modeling $-R$ package version 0.5-1. https://CRAN.R-project.org/package= semTools

Kline, R. B. (2015). Principles and practice of structural equation modeling (4th ed.). New York: Guilford Press.

Koenig, H. G. (2020). Maintaining health and well-being by putting faith into action during the COVID-19 pandemic. Journal of Religion and Health, 59, 2205-2214. https://doi.org/10.1007/ s10943-020-01035-2 
Koenig, H. G., Al-Zaben, F., \& VanderWeele, T. J. (2020). Religion and psychiatry: Recent developments in research. Bjpsych Advances, 26(5), 262-272. https://doi.org/10.1192/bja.2019.81

Koenig, H. G., \& Al Shohaib, S. (2014). Health and well-being in Islamic societies. Springer.

Koukounaras Liagkis, M., \& Ktenidis, Z. (2021). Evaluating the Francis Scale of Attitudes Towards Christianity (FSATC) and the Santa Clara Strength of Religious Faith Questionnaire (SCSRFQ) in the Greek Orthodox context. Mental Health, Religion \& Culture, 24, 1-11. https://doi.org/10.1080/ 13674676.2020.1770711

Kowalczyk, O., Roszkowski, K., Montane, X., Pawliszak, W., Tylkowski, B., \& Bajek, A. (2020). Religion and faith perception in a pandemic of COVID-19. Journal of Religion and Health, 59(6), 2671-2677. https://doi.org/10.1007/s10943-020-01088-3

Kranz, D., Niepel, C., Botes, E., \& Greiff, S. (2020). Religiosity predicts unreasonable coping with COVID-19. Advance online publication. https://doi.org/10.1037/rel0000395

Lee, S. A. (2020). Coronavirus Anxiety Scale: A brief mental health screener for COVID-19 related anxiety. Death Studies, 44(7), 393-401. https://doi.org/10.1080/07481187.2020.1748481

Lerman, S., Jung, M., Arredondo, E. M., Barnhart, J. M., Cai, J., Castañeda, S. F., Daviglus, M. L., Espinoza, R. A., Giachello, A. L., Molina, K. M., Perreira, K., Salgado, H., Wassertheil-Smoller, S., \& Kaplan, R. C. (2018). Religiosity prevalence and its association with depression and anxiety symptoms among Hispanic/Latino adults. PloS One, 13(2), e0185661. https://doi.org/10. 1371/journal.pone.0185661

Lewis, C. A., Shevlin, M., McGuckin, C., \& Navratil, M. (2001). The Santa Clara Strength of Religious Faith Questionnaire: Confirmatory factor analysis. Pastoral Psychology, 49(5), 379-384. https:// doi.org/10.1023/A:1010370728546

Lucchetti, G., Góes, L. G., Amaral, S. G., Ganadjian, G. T., Andrade, I., de Araújo Almeida, P. O., \& Manso, M. E. G. (2020). Spirituality, religiosity and the mental health consequences of social isolation during Covid-19 pandemic. International Journal of Social Psychiatry, Article 0020764020970996 https://doi.org/10.1177/0020764020970996

McDonald, R. P. (1999). Test theory: A unified treatment. Mahwah, NJ: Erlbaum.

Muthén, L. K., \& Muthén, B. O. (2002). How to use a Monte Carlo study to decide on sample size and determine power. Structural Equation Modeling, 9, 599-620. https://doi.org/10.1207/S15328007SEM0904_8

Newport, F. (2020, April 6). Religion and the COVID-19 virus in the U.S. Gallup. https://news.gallup. com/opinion/polling-matters/307619/religion-covid-virus.aspx

Ng, G. C., Mohamed, S., Sulaiman, A. H., \& Zainal, N. Z. (2017). Anxiety and depression in cancer patients: The association with religiosity and religious coping. Journal of Religion and Health, 56(2), 575-590. https://doi.org/10.1007/s10943-016-0267-y

Oliver, A., Galiana, L. \& Bustos, V. (2018). Validación de la Escala de Satisfacción con la Vida y su relación con las dimensiones del Autoconcepto en universitarios peruanos. Persona, (21), 29-44. https://doi. org/10.26439/persona2018.n021.3018

Pakpour, A. H., Plante, T. G., Saffari, M., \& Fridlund, B. (2014). The Santa Clara Strength of Religious Faith Questionnaire (SCSORF): A validation study on Iranian Muslim patients undergoing dialysis. Journal of Religion and Health, 53(6), 1885-1897. https://doi.org/10.1007/s10943-014-9856-9

Pew Research Center. (2014). Religion in Latin America. https://www.pewforum.org/2014/11/13/ religion-inlatin-america/

Pew Research Center. (2020). Most Americans say coronavirus outbreak has impacted their lives. https://www.pewresearch.org/social-trends/2020/03/30/most-americans-say-coronavirus-outbreakhas-impacted-their-lives/

Plante, T. G. (2010). The Santa Clara strength of religious faith questionnaire: Assessing faith engagement in a brief and nondenominational manner. Religions, 1(1), 3-8. https://doi.org/10.3390/ rel1010003

Plante, T. G. (2021). The Santa Clara Strength of Religious Faith Questionnaire (SCSRFQ): A brief, nondenominational, and multicultural assessment tool. In P. Wink, R. F. Paloutzian, \& K. A. Harris (Eds.), Assessing spirituality in a diverse world (pp. 445-466). Cham, Switzerland: Springer Nature Switzerland.

Plante, T. G., \& Boccaccini, M. T. (1997). The Santa Clara Strength of Religious Faith Questionnaire. Pastoral Psychology, 45(5), 375-387. https://doi.org/10.1007/BF02230993

Plante, T. G., Saucedo, B., \& Rice, C. (2001). The association between strength of religious faith and coping with daily stress. Pastoral Psychology, 49(4), 291-300. https://doi.org/10.1023/A:1004819505286

Plante, T. G., Vallaeys, C. L., Sherman, A. C., \& Wallston, K. A. (2002). The development of a brief version of the Santa Clara Strength of Religious Faith Questionnaire. Pastoral Psychology, 50(5), 359-368. https://doi.org/10.1023/A:1014413720710 
Plante, T. G., Yancey, S., Sherman, A., \& Guertin, M. (2000). The association between strength of religious faith and psychological functioning. Pastoral Psychology, 48(5), 405-412. https://doi.org/10. 1023/A:1022040605141

Plante, T. G., Yancey, S., Sherman, A., Guertin, M., \& Pardini, D. (1999). Further validation for the Santa Clara Strength of Religious Faith Questionnaire. Pastoral Psychology, 48(1), 11-21. https:// doi.org/10.1023/A:1021950628088

R Core Team. (2019). A language and environment for statistical computing. R Foundation for Statistical Computing. http://www.r-project.org/

Raykov, T., \& Hancock, G. R. (2005). Examining change in maximal reliability for multiple-component measuring instruments. British Journal of Mathematical and Statistical Psychology, 58(1), 65-82. https://doi.org/10.1348/000711005X38753

Rizopoulos, D. (2006) ltm: An R package for latent variable modelling and item response theory analyses. Journal of Statistical Software, 17(5), 1-25. https://doi.org/10.18637/jss.v017.i05

Rodríguez, T., Vilca, L. W., Carbajal-León, C., White, M., Vivanco-Vidal, A., Saroli-Araníbar, D., ... \& Moreta-Herrera, R. (2021). Coronavirus Anxiety Scale: New psychometric evidence for the Spanish version based on CFA and IRT models in a Peruvian sample. Death Studies, 1-10. https://doi.org/10. 1080/07481187.2020.1865480

Rosenman, R., Tennekoon, V., \& Hill, L. G. (2011). Measuring bias in self-reported data. International Journal of Behavioural and Healthcare Research, 2(4), 320-332. https://doi.org/10.1504/IJBHR. 2011.043414

Rosseel, Y. (2012). lavaan: An R package for structural equation modeling. Journal of Statistical Software, 48(2), 1-36. https://doi.org/10.18637/jss.v048.i02

RStudio Team. (2018). RStudio: Integrated development environment for R. RStudio. http://www.rstudio.com/

Samejima, F. (1997). Graded response model. In W. J. Van der Linden \& R. K. Hambleton (Eds.), Handbook of modern item response theory (pp. 85-100). New York: Springer.

Schumacker, R. E., \& Lomax, R. G. (2015). A beginner's guide to structural equation modeling. Mahwah, NJ: Erlbaum.

Sherman, A. C., Plante, T. G., Simonton, S., Adams, D. C., Burris, S. K., \& Harbison, C. (1999). Assessing religious faith in medical patients: Cross-validation of the Santa Clara Strength of Religious Faith Questionnaire. Pastoral Psychology, 48(2), 129-141. https://doi.org/10.1023/A:1022094727122

Sherman, A. C., Simonton, S., Adams, D. C., Latif, U., Plante, T. G., Burns, S. K., \& Poling, T. (2001). Measuring religious faith in cancer patients: Reliability and construct validity of the Santa Clara Strength of Religious Faith Questionnaire. Psycho-Oncology, 10(5), 436-443. https://doi.org/10.1002/ pon. 523

Somma, N. M., Bargsted, M. A., \& Valenzuela, E. (2017). Mapping religious change in Latin America. Latin American Politics and Society, 59(1), 119-142. https://doi.org/10.1111/laps.12013

Steinberg, L., \& Thissen, D. (2013). Item response theory. In J. S. Comer \& P. C. Kendall (Eds.), Oxford library of psychology. The Oxford handbook of research strategies for clinical psychology (p. 336373). New York, NY: Oxford University Press.

Storch, E. A., Roberti, J. W., Bagner, D. M., Lewin, A. B., Baumeister, A. L., \& Geffkend, G. R. (2004a). Further psychometric properties of the Santa Clara Strength of Religious Faith Questionnaire-Short Form. Journal of Psychology \& Christianity, 23(1), 51-53.

Storch, E. A., Roberti, J. W., Bravata, E., \& Storch, J. B. (2004b). Psychometric investigation of the Santa Clara Strength of Religious Faith Questionnaire-Short-form. Pastoral Psychology, 52(6), 479-483. https://doi.org/10.1023/B:PASP.0000031526.64795.41

Tan, S.-Y. (2013). Addressing religion and spirituality from a cognitive behavioral perspective. In K. I. Pargament (Ed.), APA handbook of psychology, religion, and spirituality: Vol. 2-An applied psychology of religion and spirituality (pp. 169-187). Washington, DC.: American Psychological Association. https://doi.org/10.1037/14046-008

Van de Schoot, R., Lugtig, P., \& Hox, J. (2012). A checklist for testing measurement invariance. European Journal of Developmental Psychology, 9(4), 486-492. https://doi.org/10.1080/17405629.2012.686740

Walker, J. J., \& Longmire-Avital, B. (2013). The impact of religious faith and internalized homonegativity on resiliency for Black lesbian, gay, and bisexual emerging adults. Developmental Psychology, 49(9), 1723-1731. https://doi.org/10.1037/a0031059

WIN Gallup International. (2017). Religion prevails in the world. WIN/Gallup International. https://www. gallup-international.bg/en/36009/religion-prevails-in-the-world/

Wink, P., Paloutzian, R. F., \& Harris, K. A. (2021). Assessing spirituality in a diverse world. Springer.

Wnuk, M. (2017). A psychometric evaluation of the Santa Clara Strength of Religious Faith Questionnaire among students from Poland and Chile. Pastoral Psychology, 66(4), 551-562. https://doi.org/10.1007/ s11089-017-0754-4 
Wu, A. D., Zhen, L., \& Zumbo, B. D. (2007). Decoding the meaning of factorial invariance and updating the practice of multi-group confirmatory factor analysis: A demonstration with TIMSS data. Practical Assessment, Research, and Evaluation, 12(1), Article 3. https://scholarworks.umass.edu/pare/vol12/ iss $1 / 3$.

Ziegler, M., \& Hagemann, D. (2015). Testing the unidimensionality of items. European Journal of Psychological Assessment, 31, 231-237. https://doi.org/10.1027/1015-5759/a000309

Publisher's Note Springer Nature remains neutral with regard to jurisdictional claims in published maps and institutional affiliations. 